\title{
Work-focused therapy for common mental disorders: A naturalistic study comparing an intervention group with a waitlist control group
}

\author{
Ragne G.H. Gjengedal ${ }^{a, e, *}$, Silje E. Reme ${ }^{\mathrm{b}}$, Kåre Osnes ${ }^{\mathrm{a}}$, Suzanne E. Lagerfeld ${ }^{\mathrm{c}}$, \\ Roland W.B. Blonk ${ }^{\mathrm{d}, \mathrm{f}}$, Kenneth Sandin ${ }^{\mathrm{a}, \mathrm{e}}$, Torkil Berge ${ }^{\mathrm{a}}$ and Odin Hjemdal ${ }^{\mathrm{a}, \mathrm{e}}$ \\ ${ }^{a}$ Diakonhjemmet Hospital, Oslo, Norway \\ ${ }^{\mathrm{b}}$ University of Oslo, Oslo, Norway \\ ${ }^{\mathrm{c}}$ Instituut Gak, Hilversum, The Netherlands \\ ${ }^{\mathrm{d}}$ Tilburg University, Tilburg, The Netherlands \\ ${ }^{\mathrm{e}}$ Norwegian University of Science and Technology, Trondheim, Norway \\ ${ }^{\mathrm{f}}$ TNO, Institute for Applied Scientific Research, The Netherlands
}

\begin{abstract}
.
BACKGROUND: Common mental disorders (CMD) are leading causes of sickness absence. Treatments for CMD that both reduce symptoms and support work participation urgently need to be developed.

OBJECTIVE: Determine the potential effects of work-focused therapy combining work interventions with either meta cognitive therapy or cognitive behavioural therapy (W-MCT/CBT) for patients with CMD on sick leave.

METHODS: Naturalistic study with a quasi-experimental approach. Pre- and post-scores (return to work, symptoms, returnto-work self-efficacy, clinical recovery from depression and anxiety) were compared between the intervention group $(n=87)$ who received immediate treatment over an average of 10.40 sessions $(S D=3.09)$ and the non-randomized waitlist control group $(n=95)$ that had waited an average of 11.18 weeks $(S D=2.29)$.

RESULTS: Significantly more patients returned fully to work in the intervention group (41.4\%) than the control group $(26.3 \%)$. Effect sizes for self-efficacy scores, depression and anxiety were large in the intervention group $(d=1.28,1.01$, $1.58)$, and significantly lower in the control group $(d=0.60,0.14,0.45)$. Significantly more patients in the treatment group than control group recovered from depression (54.1\% vs. $12.8 \%)$ and anxiety $(50.0 \%$ vs. $10.6 \%)$.
\end{abstract}

CONCLUSIONS: W-MCT/CBT may be an effective intervention for patients on sick leave due to CMD.

Keywords: Return to work, sick leave, work-focused metacognitive and cognitive therapy, self-efficacy, mental health

\section{Introduction}

*Address for correspondence: Ragne G.H. Gjengedal. Tel.: +4792663532; E-mail: Ragne.gjengedal@diakonsyk.no.

Depression and anxiety are major contributors to the global burden of disease and leading causes 
of sickness absence and long-term work incapacity across the member countries of the Organisation for Economic Co-operation and Development (OECD) $[1,2]$. These common mental disorders (CMD) affect one-sixth of the working population at any given time, and two-thirds of new disability pensions in the OECD are due to poor mental health [3]. CMD are associated with enormous economic and social costs for employees, employers and society [4-6]. Norway has the highest incidence of sick leave and disability benefit caseload of all OECD countries [7]. CMD are one of the leading causes of disability pension awards and the second most common cause of sickness absence overall in Norway $[4,5]$.

Maintaining employment is important for ensuring a high quality of life for most people, and work provides both mental and physical health benefits [8, 9]. Individuals with anxiety or depression are twice as likely to be unemployed and have much higher risks of living in poverty and social marginalization, which in turn are associated with risk of future health problems [3, 10]. The chances of an employee ever returning to work decrease the longer a patient is absent from work due to sick leave [11-13]. Therefore, it is vitally important that patients on sick leave due to CMD can access interventions that both reduce their symptoms and increase the probability of returning to work.

Standard cognitive behavioural therapy (CBT) is considered best practice in the treatment of CMD [14, 15]. Metacogntive therapy (MCT) is a relatively new approach that has demonstrated very good outcomes in treating the symptoms of anxiety and depression; a recent review indicated MCT provided a superior effect compared to CBT [16].

Although both CBT and MCT are effective for treating the symptoms of CMD, the evidence suggests that symptom-reduction alone may not be sufficient to ensure return to work $[17,18]$. The limited effects of psychotherapeutic interventions on the probability of an individual returning to work may be the result of their primary focus on symptom reduction, with little attention given to work-related problems [19-21]. The multifactorial nature of return to work may explain why symptom reduction alone does not automatically lead to a return to work. A broad variety of incentives and risk factors must be addressed, to ensure a successful return to work process. Thus, a variety of psychological interventions have been specifically developed to target workplace processes and simultaneously alleviate symptoms and reduce the duration of sick leave $[22,23]$.
Meta-analyses have indicated that work-focused psychological treatment may reduce both the duration of sick leave and symptoms, though effect sizes were small [23, 24]. One potential explanation for these inconclusive findings may be a lack of integration between the disorder-specific treatment protocols and the return to work interventions [25].

Recent research on integrated therapy in the Netherlands and Germany found that work-focused cognitive behavioural therapy (W-CBT) reduced sickness absence for patients with CMD more effectively than standard CBT alone [26, 27], even though W-CBT and CBT led to the same level of symptom reduction. W-CBT incorporates disorder-specific and work-focused interventions to facilitate workrelated exposure, strengthening coping skills with work tasks and promoting an early graded return to work. Specifically focusing on the return to work process in combination with therapy can enhance both functional and symptom recovery and increase selfefficacy in return to work $[26,28]$.

Self-efficacy has become an important concept in recent return-to-work research. A number of studies have indicated that self-efficacy is a strong and modifiable prognostic factor during work reintegration [29-31]. Self-efficacy refers to individual's confidence in their ability to perform certain behaviours effectively [32]. According to Bandura (2006), the concept of self-efficacy is best understood as mastery expectancies related to specific domains of a person's life, which can be modified by experiences, verbal persuasions and social support [33]. To capture a person's self-efficacy during the return to work process the Return to Work Self-Efficacy scale (RTW-SE) has been specifically developed [34].

The RTW-SE score quantifies a person's confidence in his or her ability to return to work and perform work tasks despite suffering from CMD $[31,34]$. Recent research has indicated that both the baseline RTW-SE score and increases therein are robust predictors of return to work [31, 35-37]. These findings indicates the importance of targeting self-efficacy in return-to-work interventions and monitoring RTW-SE scores during therapy.

In this naturalistic treatment study we examined the changes in return to work, RTW-SE scores, and symptoms of depression and anxiety during WMCT/CBT in an ecologically valid treatment setting. Improvements in patients with CMD are not always attributable to the treatment, as natural spontaneous recovery is common [38, 39]. However, previous intervention studies on recovery after sick leave, 
provide limited insight as the control groups often received "care as usual". Therefore, in this study, we explored the differences between the treatment intervention and natural improvement by applying a quasi-experimental approach, which included comparing a non-randomized waitlist control group with a treatment intervention group that began treatment immediately after referral. To our knowledge this is the first naturalistic study to investigate W-MCT/CBT for patients with CMD using a waitlist control group.

The primary objective of this study was to determine the potential effectiveness of W-MCT/CBT on return to work in the intervention group, in comparison with a waitlist control group. The secondary objectives were to compare the changes in RTW-SE scores, depression and anxiety levels, and the proportion of patients who recovered from depression and anxiety between the intervention and control groups.

\section{Study design}

\subsection{Participants and study context}

Data were obtained for patients treated at an outpatient clinic at Diakonhjemmet Hospital in Norway, over a 3-year period (2013-2016). Patients were referred to the clinic by their general practitioners (GPs). Elligble patients had to be on graded or full sick leave and have a score of 14 or more on the Beck Depression Inventory second edition (BDI-II) [40]. A score of 14 was selected to ensure that all patients had clinically significant depressive symptoms. This cut off is used when assessing clinically significant changes in clinical treatment trials [41], which enables the comparison of this study with the results of other clinical treatment trials.

The clinical psychologists and psychiatrists responsible for treatment diagnosed the participants in accordance with the national guidelines for assessments in secondary care and the International Classification of Diseases-10 (WHO, 1992). All participants' had a primary diagnosis of mildto-moderate depressive disorders, anxiety disorders or adjustment disorders. Diagnoses of comorbidity were not registered in the current study. The exclusion criteria followed the intake procedures of the clinic; patients with severe mental disorders (e.g. bipolar disorder, cluster A or B personality disorder, or psychosis), high suicide risk or substance abuse were excluded. As this study explored effects of treatments on return to work among patients on sick leave, we also excluded patients who were unemployed, studying, on parental leave, receiving disability or unemployment benefits, or working without sick leave benefits at intake.

Each patient's GP certified their sick leave during the intervention. Employees on sick leave in Norway receive $100 \%$ coverage of lost income from day 1 for up to 52 weeks. The employers cover the first 16 days of sick leave, and the Norwegian Welfare and Labour Administration (NAV) covers the remainder of the 52-week period. After 52 weeks, patients may be eligible for long-term benefits that correspond to approximately $66 \%$ of their previous salary. The employee, the employer, GP, and representatives from the NAV participate in dialogue meetings during sick leave periods as a regulatory requirement. The purpose of the dialogue meetings is to make a followup plan and discuss work-related activities with the aim of helping the employee return to work. Recently, the Norwegian authorities have strongly encouraged the use of graded sick leave, though GPs and employers have no legal obligations to promote a gradual return to work.

\subsection{Procedures}

We applied a quasi-experimental approach, in which a group of patients that started treatment immediate after referral was compared with patients on a waitlist (Fig. 1). Quasi-experimental approaches are recommended in health-service research when strict randomization is not feasible for practical or ethical reasons [42]. The clinic operates a waitlist; the duration of waiting varied due to different factors, such as seasonal fluctuations in referrals from GPs and capacity restrictions at the clinic. This naturalistic variation made it possible to compare a non-randomized waitlist control group with the patients in the intervention group who received treatment immediately.

The groups were selected from the study sample according to predefined criteria related to waiting time, number of treatment sessions and questionnaire completion.Patients in the intervention group did not experience a delay between the intake assessment session and the first treatment session, while patients in the control group waited for more than 60 days for treatment after their intake assessment session. A cut-off of 60 days was selected because this was a frequent waiting time. Furthermore, approximately 10 sessions of therapy can be delivered within 60 days. Clinical guidelines for anxiety and depressive disorders often indicate that treatment benefits typically 


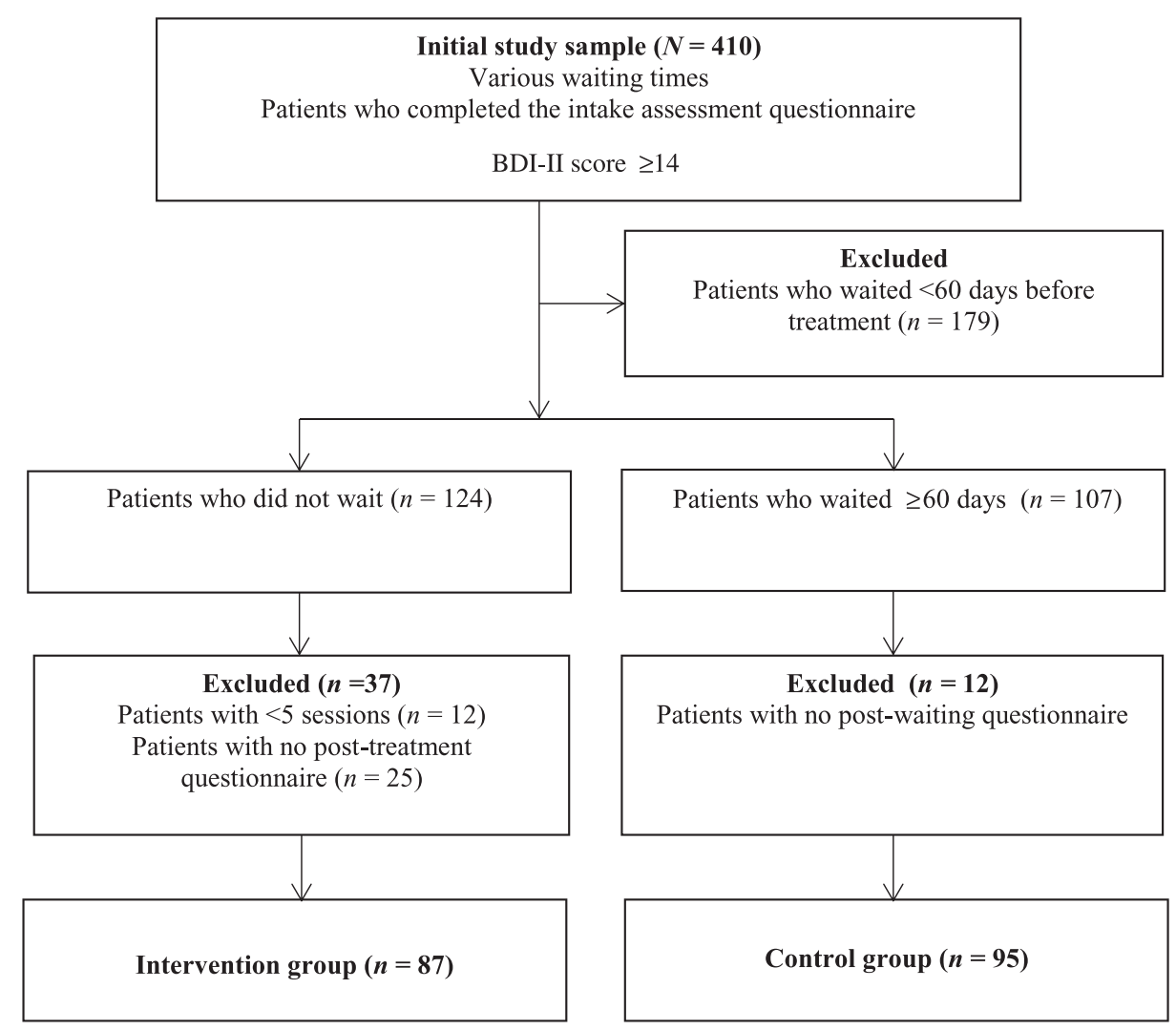

Note: BDI-II = Beck Depression Inventory-second edition

Fig. 1. Flow diagram of the study samples.

appears after 10-15 sessions, while the treatment effects for highly specific anxiety disorders such as panic and phobias reportedly often occur after around only five sessions [43]. Research on interventions aimed at enhancing return to work also indicates that at least five sessions are needed [18]. Thus, only patients who attended a minimum of five sessions were eligible for inclusion in the intervention group. As shown in Fig. 1, of the 410 patients who were potentially eligible for the study sample, 95 were included in the control group and 87 were included in the intervention group. Assuming response rates for full return to work of 0.2 in the control group and 0.4 in the treatment group, a power analysis showed that 90 patients in each group gave an $80 \%$ chance of detecting a significant difference at a two-sided significance level of 0.05 [44].

The patients in the intervention group attended a mean of 10.40 sessions $(S D=3.09$, duration $M=17.74$ weeks $(S D=6.67)$. The patients in the control group waited for an average of $M=11.18$ weeks
$(S D=2.2)$. The clinic conducts a routine outcome monitoring system, in which the same set of questionnaires was administered to the participants at pre-and post-waiting in the control group and pre- and posttreatment in the intervention group.

\subsection{Intervention}

The treatment applied in this study integrating therapeutic interventions to enhance coping at work with evidence-based psychotherapy [26]. Two types of therapy were used: MCT or CBT. These treatments both deal with maladaptive cognitions [45], are timelimited with a typical treatment duration of $8-10$ sessions, and require active cooperation between the therapist and patients during problem-formulation and the disorder-specific interventions. CBT refers to a class of interventions that focuses on challenging the validity and function of maladaptive negative automatic thoughts, reducing emotional distress, and modifying problematic behaviours [15]. MCT is a 
relatively new therapy aimed at challenging meta cognitions and psychological processes such as rumination, worry and threat monitoring. Metacognitions are beliefs about thoughts, such as whether it is beneficial to ruminate and worry, and whether thought processes are uncontrollable or dangerous. Examples of metacognitions are "Analysing the cause of my depression and failures at work will help me find answers", and "I can't control my thinking and stop worrying". MCT targets erroneous metacognitions using behaviour techniques, verbal reattribution and treatment-specific techniques such as attention training, detached mindfulness and postponement of rumination [45]. Whether the patients in this study received MCT or CBT, they were encouraged to address work-related issues and to use the workplace as an arena for testing and developing coping skills during therapy. It was important for the intervention to facilitate a gradual return to work within the context of therapy. The therapists performed workplace analyses during the therapy sessions, and outlined a return-to-work plan with each patient, which was also communicated to the patient's GP. A typical workplace analysis contained specific questions about working conditions; work and life balance; the nature of the work tasks and possible adjustments; relations to colleagues and managers; the patient's motivation for work and their understanding of how work affected their mental symptoms.

The patients' ambivalence concerning sick leave and return to work was articulated and examined in a collaborative way, and the therapists provided psychoeducation about work and mental health. Graded activity and adjustments at work were planned to enhance self-efficacy and help patients cope with setbacks during the reintegration process. A plan for communication at work was made, since stigma associated with mental illness frequently represents a barrier to receiving support from employers and colleagues when returning to work $[3,46]$.

The therapists in the study were regularly supervised. However adherence to treatment protocols was not monitored or assessed as this study was carried out in a naturalistic outpatient treatment setting. The therapists had autonomy to choose between the interventions (MCT or CBT) based on the clinical profiles of individual patients and the therapist did not follow a work-focused session-to-session manual; instead they tailored the work-related interventions according to the needs of individual patients.

The participating therapists comprised 20 clinical psychologists, three psychiatrists and two psychiatric nurses. The therapists developed individual treatment plans based on the principal diagnosis of each patient according to evidence-based, disorder-specific manuals as defined in the Norwegian national guidelines and The UK National Institute for Health and Clinical Excellence [47, 48]. The patients in the control group only received the treatment provided by their GP. Medication was prescribed by the patient's GP in accordance with national clinical guidelines for all patients in the study.

\subsection{Measures}

\subsubsection{Primary outcome}

The primary outcome of the study was full return to work. Patients reported their work status on the questionnaires using the alternatives of full sick-leave, partial sick-leave and fully working, other benefits, or unemployed.

\subsubsection{Secondary outcomes}

The RTW-SE [34] is an 11-item scale that measures expectations about fulfilling the work role and handling work tasks when the respondents return to work. The 11 items are scored from 1 to 6 , with higher scores indicating higher levels of self-efficacy. The internal consistency of this scale in the present study was high, with a Cronbach's alpha coefficient of 0.90 .

The BDI-II [40], a commonly used self-report measure for estimating the severity of depression, consists of 21 items that are rated on a four-point Likert scale ranging from 0 to 3 . The Cronbach's alpha coefficient of the BDI-II in the present study was 0.89 .

The Beck Anxiety Inventory (BAI) [49] is a 21-item self-report inventory for assessing anxiety symptoms. Each item is rated on a four-point Likertscale ranging from 0 to 3 . The Cronbach's alpha coefficient of the BAI was 0.90 .

The highest coefficient for the correlation between RTW-SE, BDI-II and BAI scores was $r=0.42$.

\subsection{Statistical analysis}

SPSS version 24.0 (IBM) was used to analyse the data. Baseline values for the control and intervention groups were compared using the independent $t$-test for continuous variables and Fisher's exact test for categorical variables. Effect sizes were calculated using Cohen's $d$ and pooled SD values [50]. The paired-sample $t$-test was used to compare pre- and post-scores within the intervention group and within the control group. Mixed model ANOVA was adopted 
to compare treatment response between the intervention and control group.

Fisher's exact test was used to investigate return to work using categorical variables. The recovery rates for depression and anxiety were evaluated by the Reliable Change Index (RCI), using the procedures of Jacobson and Truax (1991) and based on the norms described by Seggar et al. (2002) and Gillis et al. (1995) [51-53]. The RCI is an appropriate tool for assessing whether the changes in symptom scores between pre- and post-assessment are statistically reliable [51]. To demarcate the clinical range, a cut-off score of 14 was used for the BDI-II and 15 for the BAI. The change in symptoms were classified as deteriorated if BDI-II and BAI score increased by at least 9 points between pre- and post- treatment; unchanged if the score increased or decreased by less than 9; improved if the score decreased by 9 points, and recovered if the score decreased by at least 9 points and the post-treatment score was 14 or less for the BDI-II and 15 or less for the BAI. Missing data on individual items were replaced by weighted means [35].

\subsection{Ethical approval}

This study qualified as health-service research and was therefore approved in advance by the Norwegian Data Protection Authority. Patients signed an informed-consent form and could withdraw their consent without providing any explanation. The study was conducted according to the principles of the Helsinki Declaration.

\section{Results}

\subsection{Participant characteristics}

Table 1 presents an overview of the characteristics of the patients at intake. Mean patient age was 38.7 years and there were more females $(74.9 \%)$ than males. The primary diagnoses were current or recurrent depressive disorders $(53.2 \%, n=218)$, anxiety disorders $(17.1 \%, n=70)$, mixed anxiety and depression $(12.1 \%, n=50)$, and adjustment disorders $(12 \%, n=49)$; the remaining $5.6 \%(n=23)$ of patients had other primary diagnoses, such as hypochondria, eating disorders or sleeping disorders. All included patients had BDI-II scores above the clinical cutoff for depression on the assessment questionnaire $(\geq 14)$. The control group and intervention group were compared using the independent $t$-test for continuous variables and Fisher's exact test for categorical variables. No statistically significant differences in socio demographic characteristics, BDI-II, BAI or RTWSE scores, or the numbers of patients on full and partial sick leave were observed between the intervention and control groups at intake (Table 1).

\subsection{Primary outcome}

Fisher's exact test revealed that the proportion of patients achieving full return to work at the end of treatment was significantly higher in the intervention group $(41.4 \%, n=36)$ than the control group $(26.3 \%$, $n=25 ; p=0.041$; Table 2).

Table 1

Patient characteristics and sociodemographics features at baseline

\begin{tabular}{|c|c|c|c|c|c|c|c|c|c|c|c|c|}
\hline & \multicolumn{4}{|c|}{$\begin{array}{l}\text { Study sample } \\
\qquad(N=410)\end{array}$} & \multicolumn{4}{|c|}{$\begin{array}{l}\text { Control group } \\
\quad(n=95)\end{array}$} & \multicolumn{4}{|c|}{$\begin{array}{l}\text { Intervention group } \\
\quad(n=87)\end{array}$} \\
\hline & $n$ & $\%$ & Mean & SD & $\bar{n}$ & $\%$ & Mean & SD & $\bar{n}$ & $\%$ & Mean & SD \\
\hline Age, years & & & 38.7 & 10.1 & & & 37.4 & 9.4 & & & 38.7 & 10.7 \\
\hline \multicolumn{13}{|l|}{ Gender } \\
\hline Male & 103 & 25.1 & & & 22 & 23.2 & & & 27 & 31.0 & & \\
\hline \multicolumn{13}{|l|}{ Marital status } \\
\hline Living with partner & 241 & 58.8 & & & 59 & 62.1 & & & 51 & 58.6 & & \\
\hline \multicolumn{13}{|l|}{ Education } \\
\hline Primary 1-9 years & 18 & 4.4 & & & 5 & 5.3 & & & 3 & 3.4 & & \\
\hline Senior high $10-12$ years & 94 & 22.9 & & & 20 & 21.1 & & & 17 & 19.5 & & \\
\hline University $\geq 13$ years & 286 & 69.8 & & & 68 & 70.8 & & & 65 & 74.7 & & \\
\hline \multicolumn{13}{|l|}{ Work status } \\
\hline Partial sick leave & 203 & 49.5 & & & 43 & 45.3 & & & 44 & 50.6 & & \\
\hline Full sick leave & 207 & 50.5 & & & 52 & 54.7 & & & 43 & 49.4 & & \\
\hline RTW-SE & & & 2.96 & 0.98 & & & 2.91 & 0.95 & & & 2.85 & 0.94 \\
\hline BDI-II & & & 27.7 & 8.3 & & & 27.0 & 8.9 & & & 27.7 & 7.4 \\
\hline BAI & & & 19.0 & 11 & & & 17.3 & 10.6 & & & 19.5 & 10.1 \\
\hline
\end{tabular}

Note. RTW-SE Return-to-Work Self-Efficacy scale, BDI-II Beck Depression Inventory-second edition, BAI Beck Anxiety Inventory, SD standard deviation. 
Table 2

Comparison of the numbers of patients fully working post-treatment in the intervention and control groups using Fisher's exact test

\begin{tabular}{|c|c|c|c|c|c|}
\hline & \multicolumn{2}{|c|}{ Intervention group $(n=87)$} & \multicolumn{2}{|c|}{ Control group $(n=95)$} & \multirow[b]{2}{*}{ Sig. } \\
\hline & $\bar{n}$ & $\%$ & $n$ & $\%$ & \\
\hline Fully working & 36 & 41.4 & 25 & 26.3 & $0.041 *$ \\
\hline Partial sick leave & 34 & 39.1 & 44 & 46.3 & \\
\hline Full sick leave & 11 & 12.6 & 19 & 20.0 & \\
\hline Unknown work status & 6 & 6.9 & 7 & 7.4 & \\
\hline
\end{tabular}

Note.* $p<0.05$.

Table 3

Descriptive results for the BDI-II, BAI and RTW-SE. Paired-sample $t$-tests for comparisons of the pre- and post-scores within the intervention and control groups are shown, along with Cohen's d effect size. Mixed-model ANOVA, group $\times$ time interactions, was used to compare the differences in the pre- and post-scores of the invervention and control group

\begin{tabular}{|c|c|c|c|c|c|c|c|c|c|}
\hline & \multirow[b]{2}{*}{$n$} & \multicolumn{2}{|c|}{ Pre-treatment } & \multicolumn{2}{|c|}{ Post-treatment } & \multicolumn{2}{|c|}{ Within groups } & \multicolumn{2}{|c|}{$\begin{array}{c}\text { Interaction effects } \\
\text { Group } \times \text { time }\end{array}$} \\
\hline & & Mean & SD & Mean & SD & $t$ & $d$ & $\mathrm{~F}$ & $\eta_{\mathrm{p}}^{2}$ \\
\hline \multicolumn{10}{|l|}{ RTW-SE score } \\
\hline Intervention group & 82 & 2.86 & 0.95 & 4.13 & 1.03 & $9.16 * * *$ & 1.28 & $8.91 * *$ & 0.069 \\
\hline Control group & $41^{\dagger}$ & 3.04 & 0.99 & 3.65 & 1.01 & $4.06^{* * *}$ & 0.60 & & \\
\hline \multicolumn{10}{|l|}{ BDI-II score } \\
\hline Intervention group & 85 & 27.71 & 7.37 & 13.67 & 10.15 & $12.76^{* * *}$ & 1.58 & $47.16^{* * *}$ & 0.21 \\
\hline Control group & 94 & 26.99 & 8.96 & 22.65 & 10.26 & $4.83^{* * *}$ & 0.45 & & \\
\hline \multicolumn{10}{|l|}{ BAI score } \\
\hline Intervention group & 85 & 19.56 & 10.03 & 10.09 & 8.60 & $9.30 * * *$ & 1.01 & $38.49 * * *$ & 0.18 \\
\hline Control group & 91 & 17.46 & 10.69 & 16.02 & 9.86 & 1.77 & 0.14 & & \\
\hline
\end{tabular}

Note. RTW-SE = Return-to-Work Self-Efficacy scale, BDI-II = Beck Depression Inventory-second edition, BAI = Beck Anxiety Inventory, ${ }^{\dagger}$ Differences in $\mathrm{n}$ due to error in administrative routines. $* p<0.05, * * p<0.01, * * * p<0.001$.

Table 4

Clinical recovery rates for depression and anxiety based on Beck Depression Inventory and Beck Anxiety Inventory

\begin{tabular}{lccccc}
\hline & & \multicolumn{2}{c}{ The Reliable Change Index } \\
\cline { 2 - 6 } & $n$ & Deteriorated & Unchanged & Improved & Recovered \\
\hline BDI-II Intervention group & 85 & $2.4 \%$ & $23.5 \%$ & $6.0 \%$ & $54.1 \%$ \\
BDI-II Control group & 94 & $6.4 \%$ & $69.1 \%$ & $11.7 \%$ & $12.8 \%$ \\
BAI Intervention group & 54 & $1.9 \%$ & $33.3 \%$ & $14.8 \%$ & $50.0 \%$ \\
BAI Control group & 47 & $2.1 \%$ & $80.9 \%$ & $6.4 \%$ & $10.6 \%$ \\
\hline
\end{tabular}

Note. Percentage of patients are presented for each category of change. BDI-II = Beck Depression Inventory-second edition, BAI = Beck Anxiety Inventory.

\subsection{Secondary outcomes}

The intervention group achieved significantly greater improvements in the RTW-SE, BDI-II and BAI scores than the control group (Table 3). The effect sizes for all measures in the intervention group were large, ranging from $d=1.01$ to 1.58 . In the control group, the improvements in the RTW-SE $(d=0.60)$ and BDI-II $(d=0.45)$ scores between preand post-treatment were statistically significant; however, the improvement in the BAI score between preand post-treatment was not statistically significant $(d=0.14)$.

A mixed model ANOVA was used to compare the improvements in the RTW-SE, BDI-II and BAI scores in the intervention and control group (Table 3). The group $\times$ time interaction terms were significant for the RTW-SE, BDI-II and BAI, and showed advantages for the intervention group over the control group for all three measures.

Table 4 presents the reliable clinical changes and indicates that $54.1 \%(45 / 85)$ of patients in the intervention group met the criteria for recovery from depression at post-treatment compared to only $12.8 \%$ (12/94) of the patients in the control group (Fisher's exact test, $p<0.01)$. A total of $50.0 \%$ (27/54) of the patients in the intervention group recovered from anxiety compared to $10.6 \%(5 / 47)$ in the control group (Fisher's exact test, $p<0.01$ ).

\section{Discussion}

To our knowledge this is the first study of an immediate intervention group and a control waitlist group 
to investigate the effectiveness of $\mathrm{W}-\mathrm{MCT} / \mathrm{CBT}$ on return to work, self-efficacy and symptom reduction for patients on sick leave due to CMD. The main finding was that significantly more patients in the intervention group returned fully to work after treatment compared to the patients who waited for treatment in the control group. Moreover, treatment led to significantly larger improvements in self-efficacy, treatment effect sizes and recovery rates compared to the patients that waited for treatment.

The results of this study are consistent with studies from the Netherlands and Germany showing that W-CBT effectively promotes return to work and also significantly reduces symptoms [23, 26, 27]. The efficacy of W-MCT/CBT in increasing return to work is likely to be related to the combination of highly efficacious therapies for CMD combined with a focus on work.

This treatment promotes graded exposure and mastery experiences in the workplace, which are especially relevant for patients on sick leave due to CMD. Therapeutic interventions that are closely tailored to the work situation of individual patients can address the safety behaviours, avoidance and negative thinking processes (e.g. rumination and worry) that reduce an individual's function in the workplace and negatively biases their self-assessments of the ability to work $[54,55]$. W-MCT/CBT may lead to development of improved coping strategies that increase patients' confidence in their ability to perform both work tasks and handle symptoms when returning to work, resulting in higher RTW-SE scores [54].

Recent findings indicate that achieving certain threshold RTW-SE scores (within the range of 3.8 to 4.5 ) increases the probability of returning to work [28, 31]. The mean RTW-SE score for the intervention group in the present study increased from 2.86 to $4.13(d=1.28)$, thus these patients moved from low to high RTW-SE scores based on the previously suggested threshold range [31]. In comparison, while the RTW-SE scores of the patients in the control group increased significantly from 3.04 to 3.65 $(d=67)$, their post-waiting scores remained below the suggested range for high RTW-SE scores. These findings support the notion that W-MCT/CBT may enhance the probability of patients returning to work by increasing self-efficacy.

The clinical recovery rates for depression and anxiety were significantly higher in the intervention group (54.7\% and 50.0\%) than in the control group (12.8\% and $10.6 \%$ ).
Similarly, the effect sizes for depression and anxiety after treatment were significantly greater in the intervention group than in the control group after waiting. Depression scores also improved significantly in the control group $(d=0.45)$, but patients in the control group still reported symptom scores in the moderate depression range after waiting (mean BDIII score $=22.65$ ). There was no significant decrease in anxiety symptoms in the control group $(d=0.14)$, consistent with previous findings of greater symptom fluctuations in depressive disorders than in anxiety disorders [56, 57].

The large effect sizes for symptom reduction observed in the intervention group (1.01 to 1.58) are in the range of or higher than the effect sizes $(0.71$ to 1.02) determined in meta-analysis of disorder specific CBT [58-61]. This is an important finding since a recent meta-analysis of psychological treatments for individuals on sick leave due to CMD reported small effect sizes in regards to symptom changes (Hedges $g=0.21$ ) [24]. The clinical recovery rates for depression and anxiety in the present study are also higher than the clinical recovery rate of $26 \%$ for depression and $21 \%$ for anxiety among a similar group of patients receiving psychotherapy in an observational study in the UK [62].

Collectively, the high functional and symptom recovery rates reported after treatment in the intervention group of the current study indicate that W-MCT/CBT represents a promising intervention for patients struggling with impairing anxiety and depression.

\subsection{Limitations and strengths}

The main limitation of this study is the lack of a randomized control group. Therefore there is a chance that the large reduction in symptoms and the significant differences between study groups could be due to the selection criteria applied as randomisation was not conducted. However, we selected a control group with similar sick leave status, self-efficacy, symptoms and demographic characteristics at intake.

Another limitation is that the patients' work status was assessed using a single self-reported item after treatment. The effect of treatment was investigated with full return to work as a primary outcome, and relative changes in graded or full sick leave could not be evaluated due to the limited number of observations in each outcome category. Due to the naturalistic design of this study, natural variance in the duration of treatment and duration of the waitlist periode is inherent. 
Thus, future studies with a more robust design and utilization of national registry data are required to provide longer follow up data. Finally, the therapists' adherence to the treatment protocols was not monitored due to the naturalistic study design. Therefore we could not assess how effectively therapists applied the various work-focused interventions, such as the systematic use of gradual exposure to work.

Patients received either standard MCT or CBT in this study, both of which have demonstrated efficacy for treating anxiety and depression $[15,16,63]$. Further research is required to explore if the specific focus on the thought processes emphasized in MCT in combination with work interventions leads to improved effects compared to standard CBT [26, 27]. Future randomized controlled studies are required to identify if moderating effects exist.

The main strengths of this study are the large sample, the comparison with a waitlist control group and the fact that treatment was provided in a naturalistic health-care setting, which ensures high ecological validity. Randomized controlled clinical trials do not always mirror the realities of typical clinical care, so this study addresses the need for pragmatic trials with high generalizability [38, 64].

\section{Conclusion}

Overall, the results of this study imply that W-MCT/CBT can be considered as suitable treatments for patients with CMD on sick leave. W-CBT has previously been shown to be effective in the Netherlands and Germany. However, welfare systems vary between countries, which potentially complicate comparison of research on interventions to reduce sick leave in different countries. Our findings of the efficacy in the Norwegian context provide grounds for optimism that W-MCT/CBT represents a promising avenue of research to reduce sick leave and symptoms among patients with CMD.

\section{Acknowledgments}

We would like to thank all patients and therapist that participated in our study. We also thank Marianne Tranberg Bjørndal for valuable assistance in technical support and data collection.

\section{Conflict of interest}

The authors declare no conflict of interest.

\section{References}

[1] Murray CJ, Vos T, Lozano R, Naghavi M, Flaxman AD, Michaud C, et al. Disability-adjusted life years (DALYs) for 291 diseases and injuries in 21 regions, 1990-2010: a systematic analysis for the Global Burden of Disease Study 2010. The lancet. 2012;380(9859):2197-223.

[2] Cattrell A, Harris EC, Palmer KT, Kim M, Aylward M, Coggon D. Regional trends in awards of incapacity benefit by cause. Occupational medicine. 2011;61(3):148-51.

[3] OECD. Mental Health and Work: Fit Mind, Fit Job: From Evidence to Practice in Mental Health and Work. Paris: OECD Publishing; 2015.

[4] Knudsen AK, Overland S, Aakvaag HF, Harvey SB, Hotopf M, Mykletun A. Common mental disorders and disability pension award: seven year follow-up of the HUSK study. J Psychosom Res. 2010;69(1):59-67.

[5] Knudsen AK, Harvey SB, Mykletun A, Øverland S. Common mental disorders and long-term sickness absence in a general working population. The Hordaland Health Study. Acta Psychiatrica Scandinavica. 2013;127(4):287-97.

[6] Chisholm D, Sweeny K, Sheehan P, Rasmussen B, Smit F, Cuijpers P, et al. Scaling-up treatment of depression and anxiety: a global return on investment analysis. The lancet Psychiatry. 2016;3(5):415-24.

[7] OECD. Mental health and Work: Norway. 2013.

[8] Rueda S, Chambers L, Wilson M, Mustard C, Rourke SB, Bayoumi A, et al. Association of Returning to Work With Better Health in Working-Aged Adults: A Systematic Review. Am J Public Health. 2012;102(3):541-56.

[9] Waddell G, Burton AK. Is work good for your health and well-being? London, UK: The Stationary Office; 2006.

[10] Roelfs DJ, Shor E, Davidson KW, Schwartz JE. Losing life and livelihood: a systematic review and meta-analysis of unemployment and all-cause mortality. Social science \& medicine. 2011;72(6):840-54

[11] Blank L, Peters J, Pickvance S, Wilford J, MacDonald E. A systematic review of the factors which predict return to work for people suffering episodes of poor mental health. Journal of Occupational Rehabilitation. 2008;18(1): 27-34.

[12] Waddell G, Burton K, Aylward M. Work and common health problems. Journal of Insurance Medicine (New York, NY). 2007;39(2):109-20.

[13] Roelen C, Norder G, Koopmans P, Van Rhenen W, Van Der Klink J, Bültmann U. Employees sick-listed with mental disorders: who returns to work and when? Journal of Occupational Rehabilitation. 2012;22(3):409-17.

[14] Butler AC. The empirical status of cognitive-behavioral therapy: A review of meta-analyses. Clinical psychology review. 2006;26(1):17-31.

[15] Hofmann SG, Asnaani A, Vonk IJ, Sawyer AT, Fang A. The efficacy of cognitive behavioral therapy: A review of metaanalyses. Cognitive therapy and research. 2012;36(5):42740.

[16] Normann N, Emmerik AA, Morina N. The efficacy of metacognitive therapy for anxiety and depression: A metaanalytic review. Depression and Anxiety. 2014;31(5):40211.

[17] Ejeby K, Savitskij R, Öst L-G, Ekbom A, Brandt L, Ramnerö J, et al. Symptom reduction due to psychosocial interventions is not accompanied by a reduction in sick leave: results from a randomized controlled trial in primary care. Scandinavian Journal of Primary Health Care. 2014;32(2):67-72. 
[18] Blonk RW, Brenninkmeijer V, Lagerveld SE, Houtman IL. Return to work: a comparison of two cognitive behavioural interventions in cases of work-related psychological complaints among the self-employed. Work \& Stress. 2006;20(2):129-44.

[19] de Vries G, Hees HL, Koeter MW, Lagerveld SE, Schene AH. Perceived impeding factors for return-to-work after long-term sickness absence due to major depressive disorder: a concept mapping approach. PLoS One. 2014;9(1):e85038.

[20] Kidd SA, Boyd GM, Bieling P, Pike S, Kazarian-Keith D. Effect of a Vocationally-Focused Brief Cognitive Behavioural Intervention on Employment-Related Outcomes for Individuals with Mood and Anxiety Disorders. Cognitive Behaviour Therapy. 2008;37(4): 247-51.

[21] OECD. Mental Health and Work Sick on the job?: Myths and Realities about Mental Health and Work. Paris: OECD Publishing; 2012.

[22] Finnes A, Enebrink P, Ghaderi A, Dahl J, Nager A, Öst L-G. Psychological treatments for return to work in individuals on sickness absence due to common mental disorders or musculoskeletal disorders: a systematic review and meta-analysis of randomized-controlled trials. International Archives of Occupational and Environmental Health. 2018: $1-21$.

[23] Cullen K, Irvin E, Collie A, Clay F, Gensby U, Jennings $\mathrm{P}$, et al. Effectiveness of workplace interventions in return-to-work for musculoskeletal, pain-related and mental health conditions: an update of the evidence and messages for practitioners. Journal of Occupational Rehabilitation. 2018;28(1):1-15.

[24] Salomonsson S, Hedman-Lagerlöf E, Öst L-G. Sickness absence: a systematic review and meta-analysis of psychological treatments for individuals on sick leave due to common mental disorders. Psychological medicine. 2018:112.

[25] Finnes A, Ghaderi A, Dahl J, Nager A, Enebrink P. Randomized controlled trial of acceptance and commitment therapy and a workplace intervention for sickness absence due to mental disorders. J Occup Health Psychol. 2017:1-15.

[26] Lagerveld SE, Blonk RW, Brenninkmeijer V, Wijngaards-de Meij L, Schaufeli WB. Work-focused treatment of common mental disorders and return to work: a comparative outcome study. J Occup Health Psychol. 2012;17(2):220-34.

[27] Kroger C, Bode K, Wunsch EM, Kliem S, Grocholewski A, Finger F. Work-related treatment for major depressive disorder and incapacity to work: preliminary findings of a controlled, matched study. J Occup Health Psychol. 2015;20(2):248-58.

[28] Lagerveld SE. Mastery Matters: The impact of self-efficacy and work-focused therapy on return to work among employees with common mental disorders: Utrecht University; 2017.

[29] Cornelius L, Van der Klink J, Groothoff J, Brouwer S. Prognostic factors of long term disability due to mental disorders: a systematic review. Journal of Occupational Rehabilitation. 2011;21(2):259-74.

[30] Brouwer S, Amick BC, Lee H, Franche R-L, Hogg-Johnson $\mathrm{S}$. The predictive validity of the return-to-work self-efficacy scale for return-to-work outcomes in claimants with musculoskeletal disorders. Journal of Occupational Rehabilitation. 2015;25(4):725-32.

[31] Lagerveld SE, Brenninkmeijer V, Blonk RW, Twisk J, Schaufeli WB. Predictive value of work-related self-efficacy change on RTW for employees with common mental disorders. Occup Environ Med. 2017;74(5):381-3.

[32] Bandura A. The explanatory and predictive scope of selfefficacy theory. Journal of Social and Clinical Psychology. 1986;4(3):359-73.

[33] Bandura A. Guide for constructing self-efficacy scales. In: Pajares F, Urdan T, editors. Self-efficacy beliefs of adolescents. Greenwich CT: Information Age Publishing; 2006. p. 307-37.

[34] Lagerveld SE, Blonk RWB, Brenninkmeijer V, Schaufeli WB. Return to work among employees with mental health problems: Development and validation of a self-efficacy questionnaire. Work \& Stress. 2010;24(4): 359-75.

[35] Volker D, Zijlstra-Vlasveld MC, Brouwers EPM, van Lomwel AGC, van der Feltz-Cornelis CM. Return-to-work self-efficacy and actual return to work among long-term sick-listed employees. Journal of Occupational Rehabilitation. 2015;25(2):423-31.

[36] Nieuwenhuijsen K, Noordik E, van Dijk FJ, van der Klink JJ. Return to work perceptions and actual return to work in workers with common mental disorders. Journal of Occupational Rehabilitation. 2013;23(2):290-9.

[37] Black O, Keegel T, Sim MR, Collie A, Smith P. The Effect of Self-Efficacy on Return-to-Work Outcomes for Workers with Psychological or Upper-Body Musculoskeletal Injuries: A Review of the Literature. J Occup Rehabil. 2017;28:16-27.

[38] Wessely S. A defence of the randomized controlled trial in mental health. BioSocieties. 2007;2(1):115-27.

[39] Clark D, Fairburn C, Wessely S. Psychological treatment outcomes in routine NHS services: A commentary on Stiles et al. (2007). Psychological Medicine. 2008;38(5): 629-34.

[40] Beck AT, Steer RA, Brown GK. Beck Depression Inventoryii (bdi-ii). San Antonio, TX: Psychological Corporation. 1996.

[41] Jacobson NS, Roberts LJ, Berns SB, McGlinchey JB. Methods for defining and determining the clinical significance of treatment effects: description, application, and alternatives. Journal of Consulting and Clinical Psychology. 1999;67(3):300.

[42] Shi L. Health services research methods: Cengage Learning; 2007.

[43] Otto MW, Tolin DF, Nations KR, Utschig AC, Rothbaum BO, Hofmann SG, et al. Five sessions and counting: Considering ultra-brief treatment for panic disorder. Depression and Anxiety. 2012;29(6):465-70.

[44] Suresh K, Chandrashekara S. Sample size estimation and power analysis for clinical research studies. Journal of Human Reproductive Sciences. 2012;5(1): 7-13.

[45] Fisher P, Wells A. Metacognitive therapy: Distinctive features: Routledge; 2009.

[46] Kirsh B, Krupa T, Luong D. How do supervisors perceive and manage employee mental health issues in their workplaces? Work. 2018;59(4):547-55.

[47] National Institute for Health and Clinical Excellence. Depression in adults: NICE guidelines; 2009.

[48] National Institute for Health and Care Excellence Anxiety: NICE guideline; 2011.

[49] Beck AT, Steer RA. Manual for the Beck anxiety inventory. San Antonio, TX: Psychological Corporation. 1990.

[50] Cohen J. Statistical power analyses for the social sciences. New York: Academic; 1988. 
[51] Jacobson NS, Truax P. Clinical significance: a statistical approach to defining meaningful change in psychotherapy research. Journal of Consulting and Clinical Psychology. 1991;59(1):12-19.

[52] Seggar LB, Lambert MJ, Hansen NB. Assessing clinical significance: application to the Beck Depression Inventory. Behavior Therapy. 2002;33(2):253-69.

[53] Gillis MM, Haaga DA, Ford GT. Normative values for the Beck Anxiety Inventory, Fear Questionnaire, Penn State Worry Questionnaire, and Social Phobia and Anxiety Inventory. Psychological Assessment. 1995;7(4):450-455.

[54] Henderson M, Harvey SB, Øverland S, Mykletun A, Hotopf $M$. Work and common psychiatric disorders. Journal of the Royal Society of Medicine. 2011;104(5):198-207.

[55] Lagerveld SE, Bultmann U, Franche RL, van Dijk FJ, Vlasveld MC, van der Feltz-Cornelis CM, et al. Factors associated with work participation and work functioning in depressed workers: a systematic review. J Occup Rehabil. 2010;20(3):275-92.

[56] Yonkers KA, Bruce SE, Dyck IR, Keller MB. Chronicity, relapse, and illness-course of panic disorder, social phobia, and generalized anxiety disorder: findings in men and women from 8 years of follow-up. Depression and anxiety. 2003;17(3):173-9.

[57] Posternak MA, Miller I. Untreated short-term course of major depression: a meta-analysis of outcomes from studies using wait-list control groups. Journal of Affective Disorders. 2001;66(2):139-46.
[58] Cuijpers P, Berking M, Andersson G, Quigley L, Kleiboer A, Dobson KS. A meta-analysis of cognitive-behavioural therapy for adult depression, alone and in comparison with other treatments. Canadian Journal of Psychiatry Revue Canadienne de Psychiatrie. 2013;58(7):376-85.

[59] Cuijpers P, Sijbrandij M, Koole S, Huibers M, Berking M, Andersson G. Psychological treatment of generalized anxiety disorder: a meta-analysis. Clin Psychol Rev. 2014;34(2):130-40.

[60] Mayo-Wilson E, Dias S, Mavranezouli I, Kew K, Clark DM, Ades AE, et al. Psychological and pharmacological interventions for social anxiety disorder in adults: a systematic review and network meta-analysis. The lancet Psychiatry. 2014;1(5):368-76.

[61] Sanchez-Meca J, Rosa-Alcazar AI, Marin-Martinez F, Gomez-Conesa A. Psychological treatment of panic disorder with or without agoraphobia: a meta-analysis. Clin Psychol Rev. 2010;30(1):37-50.

[62] Griffiths CA, Griffiths LJ. Recovery and reliable change rates for patients scoring severe on depression, anxiety or impaired functioning in a psychological therapies service: IAPT. Mental Health Review Journal. 2015;20(1):28-35.

[63] Wells A, Fisher P, Myers S, Wheatley J, Patel T, Brewin $\mathrm{CR}$. Metacognitive therapy in recurrent and persistent depression: A multiple-baseline study of a new treatment. Cognitive Therapy and Research. 2009;33(3):291-300.

[64] OECD. Mental Health and Work. Paris: OECD Publishing; 2014. 